\title{
OUTCOMES OF REFRACTORY STATUS EPILEPTICUS IN CHILDREN
}

\author{
Javeria Raza Alvi, Areeba Wasim, Mohsin Ali, Muhammad Athar Khalily, Zia-Ur-Rehman, Tipu Sultan
}

The Children's Hospital and Institute of Child Health, Lahore Pakistan

\begin{abstract}
Objective: To determine the outcome of Refractory Status Epilepticus (RSE) in children and the factors affecting the outcome. Study Design: Cross-sectional study.

Place and Duration of Study: High Dependency Unit of Pediatrics Neurology Department at the Children's Hospital and Institute of Child Health, from Aug 2019 to Mar 2020.

Methodology: This study was conducted on the children presenting with refractory status epilepticus. Structured proforma was used for recording predictive factors. Modified Rankin scale prior to the presentation and Glasgow Coma Scale at presentation were documented and compared with the discharge scores.

Results: Out of 75 children, $46(61.4 \%)$ were males with mean age of $4.43 \pm 3.47$ years. Common etiologies were acute symptomatic in $37(49.3 \%)$, progressive encephalopathy in 19 (25.3\%), static encephalopathy in 9 (11.9\%), remote symptomatic in 4 $(5.3 \%)$, acute on remote symptomatic in $3(4.0 \%)$, idiopathic and unclassified in remaining patients. Mean time between seizures onset and first benzodiazepine injection was $44 \pm 36$ minutes. Duration of RSE was <24 hours in $17(22.7 \%), 24-48$ hours in $15(20.0 \%), 48-72$ hours in $14(18.6 \%), 72-96$ hours in $12(16 \%)$ and $>96$ hours in $17(22.7 \%)$. At discharge $33(44 \%)$ returned to baseline, $31(41 \%)$ developed neurological disability while $11(15 \%)$ expired during the stay. Etiology and duration of status epilepticus had significant impact on outcome with $p$-value of 0.021 and 0.041 , respectively.

Conclusion: Acute etiology was associated with higher mortality whereas return to baseline was also fair among survivors. This poses implications for emergency management to significantly improve the treatment outcomes.
\end{abstract}

Keywords: Etiology, Outcome, Pediatrics, Status epilepticus.

How to Cite This Article: Alvi JR, Wasim A, Ali M, Khalily MA, Rehman ZU, Sultan T. Outcomes of Refractory Status Epilepticus in Children. Pak Armed Forces Med J 2021; 71(6): 2099-2103. Doi: https://doi.org/10.51253/pafmj.v71i6.4900

This is an Open Access article distributed under the terms of the Creative Commons Attribution License (https://creativecommons.org/licenses/by-nc/4.0/), which permits unrestricted use, distribution, and reproduction in any medium, provided the original work is properly cited.

\section{INTRODUCTION}

Status Epilepticus (SE) is one of the most frequent childhood neurological emergency, characterised by diverse etiology and if prolonged, associated with unfavourable outcome particularly in case of refractory status epilepticus. ${ }^{1}$ A study done in Thailand estimated that 5.10 children per 100,000 population suffered from SE every year and incidence in the developing countries is even higher. ${ }^{2,3}$ Another study quoted incidence of 20/100,000 children. ${ }^{4}$

$\mathrm{SE}$ is a life threatening problem where there are continuous seizures for 5 minutes or more, or repetitive seizures without regaining consciousness. ${ }^{3}$ It results from failure of mechanisms to terminate seizures resulting in injury to neurons and cell death. ${ }^{5}$ Duration of seizure activity from time point $\mathrm{t}-1$ to time point $\mathrm{t}-2$ is important in interpreting the short and long-term consequences. ${ }^{6}$ RSE is defined as continuous seizures that fails to respond to minimum of 2 anti-epileptic drugs including one benzodiazepine (BZD) group. It is estimated that $23-48 \%$ of status epilepticus children

Correspondence: Dr Javeria Raza Alvi, Pediatric Neurology, The Children's Hospital and Institute of Child Health, Lahore Pakistan

Received: 31 Jul 2020; revision received: 01 Jan 2021; accepted: 06 Jan 2021 progressed to RSE. ${ }^{3}$ Etiology may vary and acute infection of central nervous system is among the most common causes followed by stroke, resistant epilepsy (genetic or acquired), degenerative brain disease or intoxication. 7,8 However, at times, it is challenging to identify the underlying cause instantly, resulting in prolonged duration of seizures. ${ }^{8}$ RSE occurrence is more common with acute etiology as compared to the chronic epilepsy. ${ }^{3}$ RSE is difficult to treat, requiring high doses of antiepileptic medications, continuous infusions of benzodiazepine (midazolam or diazepam) or anaesthetic agents along with intensive monitoring of vital signs. ${ }^{7}$

Patients suffering from RSE may develop recurrent status epilepticus, acute hippocampal injury, poor quality of life, intellectual or behavioural impairment or even death. ${ }^{9}$ Mortality is associated with potentially acute etiology and impaired consciousness level at presentation but there is no significant association with gender, seizure type or history. ${ }^{10}$

Prognosis of RSE is not well characterised, particularly in local setting of Pakistan. The rationale of the study was to assess the early outcome of RSE patients, while keeping in mind the impact of outcome 
predictive factors that significantly influence the prognosis.

\section{METHODOLOGY}

It was a hospital based study conducted at the High Dependency Unit of Pediatrics Neurology Department at the Children's Hospital and Institute of Child Health, Lahore from August 2019 to March 2020 after obtaining the ethical approval from the institutional review board (ltr no. 2019-50-CHICH). Sample size was taken as 75 patients calculated by taking incidence of refractory status epilepticus as $5.10 / 100,000$ population with $95 \%$ confidence interval and 5\% margin of error using Open-Epi calculator. Sampling technique was non-probability consecutive.

Inclusion Criteria: Patients of both genders, between the ages of 1 month to 18 years presenting with convulsive refractory status epilepticus (including all seizure types irrespective of their etiology) were included in the study.

Exclusion Criteria: Patients with non-convulsive status epilepticus were excluded from this study because it was difficult to interpret the seizures and its time span and thus response to anti-epileptic drugs.

Refractory status epilepticus (RSE) was defined as continuous seizures that failed to respond to at least two anti-epileptic drugs including one from benzodiazepine (BZD) group (midazolam or diazepam) and one other antiepileptic drug either Phenytoin, Sodium Valproate or Levetiracetam. The study included children who presented with RSE in emergency or progressed to RSE after admission. Data was recorded on a pre-designed proforma including age, gender, consanguinity, any significant past history, etiology of SE, duration and time between the onset of seizure to first Benzodiazepine injection. Etiology was defined in the groups. Acute symptomatic etiology in which Status Epilepticus (SE) occurred in a previously normal child within 1 week of acute CNS injury (infection due to bacterial, viral or autoimmune causes), acute demyelinating disorders and prolonged febrile seizures. Prolonged febrile seizures were defined as SE in a normal child between the age of 6 months to 5 years during an episode of febrile illness in absence of CNS infection. ${ }^{11}$ Remote symptomatic etiology was defined as SE in a patient where CNS injury had occurred at least a week before presentation. Acute on remote symptomatic etiology was defined as SE occurring within 1 week of acute neurological insult in a previous neurologically impaired child. ${ }^{11}$ Progressive encephalopathy included neurodegenerative disorders, epileptic encephalopathies and neurometabolic disorders while static encephalopathy included cerebral palsy. Idiopathic epilepsy was defined as second unprovoked seizure leading to SE. ${ }^{11}$ Unclassified when unable to place in other categories. In order to define the etiology, neuroimaging, cerebrospinal fluid analysis (when indicated), electroencephalography (EEG) and any other relevant investigations were also performed. In subjects with previous neurological diagnosis, previous clinical details, imaging, EEG results and prescriptions were reviewed. Outcome was defined by using modified Rankin score (06) and taken as either return to baseline (0-1 score), neurological disability (2-5 score) or mortality (6 score). Neurological disability was further divided into mild (2 score), moderate (3 score) and severe disability (4-5 score) based on the mRankin score. Baseline Glasgow coma scale was also taken with modified Rankin score to help define outcome in previously neurologically disabled children. Chi-square test was used for calculating association between outcome and different variables including etiology, duration of status epilepticus and association between etiology with seizure type \& age. The $p$-value of $\leq 0.05$ was considered significant.

\section{RESULTS}

Total of 75 children were enrolled in the study out of which $46(61.4 \%)$ were males and 29 (38.6\%) were females. The mean age of the patients was $4.43 \pm 3.47$ years. Distribution of age in various subgroups showed that 32 patients $(42.7 \%)$ were between 1 month to 2 years of age, 25 patients (33.3\%) were 2-6 years, 16 patients $(21.3 \%)$ were $6-12$ years and 2 patients $(2.7 \%)$ were 12-18 years of age. Table-I represents patients characteristics and etiology. Among the enrolled patients, $33(44 \%)$ returned to baseline while 31 (41\%) developed neurological disability at discharge, and 11 (15\%) expired during hospital stay. Neurological disability was mild in $3(9 \%)$ cases, moderate in $12(39 \%)$ cases and severe in $16(52 \%)$ cases as shown in Figure1. $7(9 \%)$ patients had mild disability, 29 (39\%) patients moderate disability and 39 (52\%) severe disability shown in Figure-2. Acute symptomatic etiology was found in all age group but most common in early ages while progressive encephalopathy was almost equally divided in early infancy and late childhood $(p<0.01)$. Generalized seizures had significant association with etiology $(p<0.01)$ shown in Table-II. Etiology was associated with morbidity in terms of neurological disability and mortality with significant $p$-value (0.021). Acute symptomatic etiology was the most common cause of RSE with 37 patients $(49.3 \%)$ followed by pro- 
gressive encephalopathy in 19 patients. (25.3\%). There were most commonly seen with acute etiology and the prolonged the duration of SE, the poorer was the outcome $(p=0.041)$. There was no association across age groups, and time of onset of seizure and first benzodiazepine injection with the outcome (Table-III).

Table-I: Patient characteristics and etiology.

\begin{tabular}{|c|c|}
\hline Characteristics & Values \\
\hline Mean age, years (SD) & $4.43 \pm 3.47$ \\
\hline \multicolumn{2}{|l|}{ Gender, $\mathrm{n}(\%)$} \\
\hline Male & $46(61.4 \%)$ \\
\hline Female & $29(38.6 \%)$ \\
\hline \multicolumn{2}{|l|}{ Seizure Type, n (\%) } \\
\hline Generalized & $40(53.3 \%)$ \\
\hline Focal & $14(18.7 \%)$ \\
\hline Focal with bilateral tonic clonic & $18(24 \%)$ \\
\hline Mixed (clonic, tonic, myoclonic) & $3(4 \%)$ \\
\hline $\begin{array}{l}\text { Mean time between seizure onset and 1st } \\
\text { Benzodiazepine ( } \mathrm{min} \text { ) }\end{array}$ & $44 \pm 36$ \\
\hline \multicolumn{2}{|c|}{ Duration of Refractory Status Epilepticus , $\mathbf{n}(\%)$} \\
\hline$<24$ hours & $19(25.3 \%)$ \\
\hline 24-48 hours & $14(18.6 \%)$ \\
\hline 48-72 hours & $14(18.6 \%)$ \\
\hline 72-96 hours & $11(14.7 \%)$ \\
\hline$>96$ hours & $17(22.8 \%)$ \\
\hline \multicolumn{2}{|l|}{ Etiology, $\mathrm{n}(\%)$} \\
\hline Acute symptomatic & $37(49.3 \%)$ \\
\hline Central Nervous system infection & $29(38.6 \%)$ \\
\hline Acute Demyelinating Encephalomyelitis & $1(1.33 \%)$ \\
\hline Autoimmune encephalitis & $3(4.0 \%)$ \\
\hline Prolonged febrile status & $4(5.3 \%)$ \\
\hline Progressive encephalopathy & $19(25.3 \%)$ \\
\hline Neuro-degenerative disorder & $9(11.9 \%)$ \\
\hline Epileptic Encephalopathy & $8(10.7 \%)$ \\
\hline Metabolic disorder & $2(2.7 \%)$ \\
\hline Static encephalopathy & $9(12 \%)$ \\
\hline Remote symptomatic & $4(5.3 \%)$ \\
\hline Structural epilepsy & $3(4.0 \%)$ \\
\hline Post meningitic sequalae & $1(1.3 \%)$ \\
\hline Acute on remote symptomatic & $3(4 \%)$ \\
\hline Idiopathic epilepsy & $2(2.7 \%)$ \\
\hline Unclassified & $1(1.4 \%)$ \\
\hline
\end{tabular}

\section{DISCUSSION}

Refractory status epilepticus (RSE) affects approximately one third of patients presenting with status epilepticus. ${ }^{12,13}$ In this study of 75 enrolled children with convulsive RSE, we found that the outcome was guarded in terms of high mortality rate $(15 \%)$ and neurological disability $(40 \%)$ but with prompt management, return to baseline among survivors was also fair $(45 \%)$. According to an international study regarding the outcome, $21 \%$ of status epilepticus patients progressed to RSE, neurological sequalae were reported in
$22 \%$ cases, while case mortality rate was $11 \%$, close to our study results but $67 \%$ returned to baseline, higher than our study..$^{14}$ Another systematic review of different studies on the outcome of convulsive status epilepticus (CSE) showed a better outcome in terms of short term mortality between 2.7-5.2\% while morbidity of less than $15 \% .{ }^{13}$ A local study on convulsive SE correlated the etiology with the outcome and concluded acute etiology as a concerning cause for SE and poor outcome with $16 \%$ patients developing mental retardation, $22 \%$ mortality while only $22 \%$ recovered completely. ${ }^{15}$

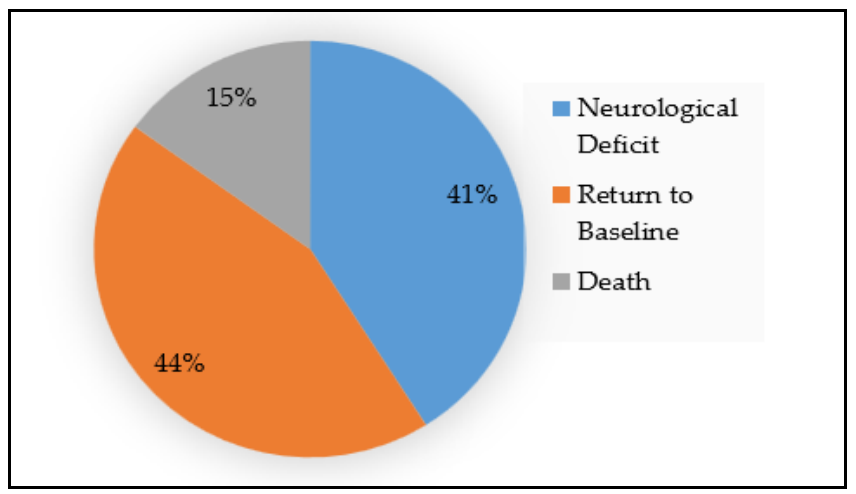

Figure-1: Percentage of patients according to outcomes of refractory status epilepticus.

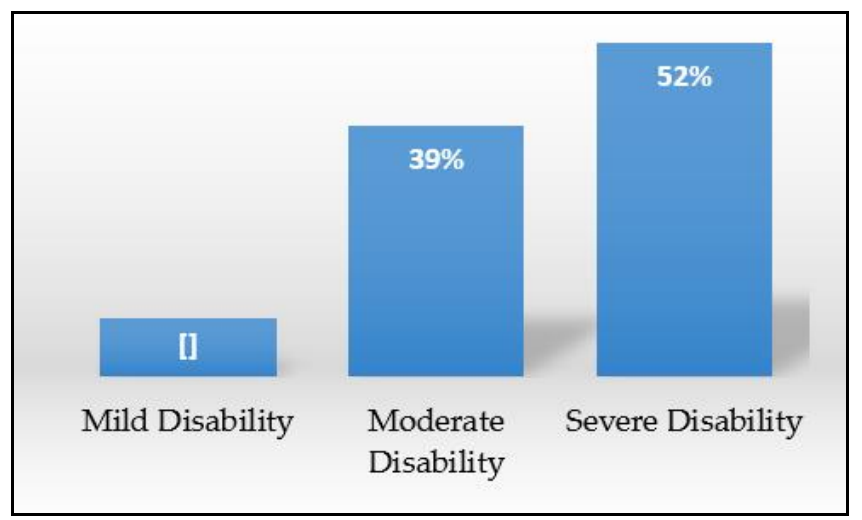

Figure-2: Percentage of patients according to disability using modified Rankin score.

Etiology is the major outcome predicting factor. ${ }^{16}$ In a study on refractory status epilepticus, they found the occurrence of RSE more common in patients with new onset seizures rather than chronic epilepsy and central nervous system infections and head trauma being more dominant etiologies in developing countries. ${ }^{3,17}$ In a study conducted on fifty children with CSE, 20 children progressed to RSE and CNS infection was the most common etiology found. ${ }^{18}$ Another study emphasized on the substantial morbidity and mortality associated with CSE and etiology but not duration of 
Table-II: Relationship of etiology with age and seizure type.

\begin{tabular}{|c|c|c|c|c|c|}
\hline \multirow{2}{*}{ Etiology } & \multicolumn{4}{|c|}{ Age in groups $(n=75)$} & \multirow{2}{*}{$p$-value } \\
\hline & 1 month - 2 years & $>2-6$ years & $>6-12$ years & $>12-18$ years & \\
\hline Acute symptomatic & $13(17.4 \%)$ & $16(21.3 \%)$ & $8(10.7 \%)$ & - & \multirow{16}{*}{0.000} \\
\hline Remote symptomatic & $1(1.3 \%)$ & $1(1.3 \%)$ & - & $2(2.7 \%)$ & \\
\hline Acute on remote & $1(1.3 \%)$ & $1(1.3 \%)$ & $1(1.3 \%)$ & - & \\
\hline Progressive encephalopathy & $8(10.7 \%)$ & $4(5.4 \%)$ & $7(9.3 \%)$ & - & \\
\hline Static encephalopathy & $6(8 \%)$ & $3(4 \%)$ & - & - & \\
\hline Idiopathic epilepsy & $2(2.7 \%)$ & - & - & - & \\
\hline \multirow[t]{3}{*}{ Unclassified } & $1(1.3 \%)$ & - & - & - & \\
\hline & \multicolumn{4}{|c|}{ Seizure type $(n=75)$} & \\
\hline & Generalized & Focal & Mixed & $\begin{array}{l}\text { Focal with bilateral } \\
\text { tonic clonic }\end{array}$ & \\
\hline Acute symptomatic & $27(36 \%)$ & $3(4 \%)$ & - & $7(9.3 \%)$ & \\
\hline Remote symptomatic & - & $4(5.3 \%)$ & - & - & \\
\hline Acute on remote & - & - & - & $3(4 \%)$ & \\
\hline Progressive encephalopathy & $8(10.7 \%)$ & $6(8 \%)$ & $2(2.7 \%)$ & $3(4 \%)$ & \\
\hline Static encephalopathy & $5(6.8 \%)$ & - & $1(1.3 \%)$ & $3(4 \%)$ & \\
\hline Idiopathic epilepsy & - & $1(1.3 \%)$ & - & $1(1.3 \%)$ & \\
\hline Unclassified & - & - & - & $1(1.3 \%)$ & \\
\hline
\end{tabular}

Table-III: Relationship between outcome and predictive factors.

\begin{tabular}{|c|c|c|c|c|}
\hline \multirow{3}{*}{ Variable } & \multicolumn{3}{|c|}{ Outcome } & \multirow{3}{*}{$p$-value } \\
\hline & Return to Baseline & Neurological Disability & Death & \\
\hline & $\mathrm{n}=33(44 \%)$ & $n=31(41 \%)$ & $\mathrm{n}=11(15 \%)$ & \\
\hline \multicolumn{4}{|l|}{ Etiology: $\mathbf{n}(\%)$} & \multirow{8}{*}{0.021} \\
\hline Acute symptomatic & $13(17.3)$ & $18(23.8)$ & $6(8.2)$ & \\
\hline Remote symptomatic & $4(5.3)$ & - & - & \\
\hline Acute on remote symptomatic & - & $1(1.3)$ & $2(2.8)$ & \\
\hline Progressive encephalopathy & $10(13.4)$ & $7(9.3)$ & $2(2.8)$ & \\
\hline Static encephalopathy & $4(5.3)$ & $5(6.6)$ & - & \\
\hline Idiopathic epilepsy & $2(2.7)$ & - & - & \\
\hline Unclassified & - & - & $1(1.2)$ & \\
\hline \multicolumn{4}{|c|}{ Duration of Refractory Status Epilepticus: $\mathbf{n}(\%)$} & \multirow{6}{*}{0.041} \\
\hline$<24$ hours & $13(17.3)$ & $4(5.3)$ & $2(2.7)$ & \\
\hline 24-48 hours & $8(10.7)$ & $5(6.7)$ & $1(1.4)$ & \\
\hline 48-72 hours & $5(6.7)$ & $8(10.5)$ & $1(1.4)$ & \\
\hline 72-96 hours & $4(5.3)$ & $6(8.0)$ & $1(1.4)$ & \\
\hline 96 hours & $3(4.0)$ & $8(10.5)$ & $6(8.1)$ & \\
\hline \multicolumn{4}{|c|}{ Mean time between onset of seizures to 1st Benzodiazepine injection: $\mathbf{n}(\%)$} & \multirow{4}{*}{0.530} \\
\hline$<10$ minutes & $7(9.4)$ & $4(5.4)$ & - & \\
\hline 10-30 minutes & $13(17.3)$ & $13(17.1)$ & $5(6.8)$ & \\
\hline$>30$ minutes & $13(17.3)$ & $14(18.5)$ & $6(8.2)$ & \\
\hline
\end{tabular}

status epilepticus was the main determinant. ${ }^{19} 53.3 \%$ children in our study also had acute etiology including both acute symptomatic and acute on remote symptomatic but about $47 \%$ patients were previously diagnosed with epilepsy and their etiology included progressive and static encephalopathy, remote symptomatic and genetic epilepsy. This is close to the western data on RSE that showed forty percent of the children presenting with SE had previous neurological abnormality and fifteen percent had history of epilepsy. ${ }^{17}$ It was reported in another study that etiology was the most important factor of outcome of status epilepticus but they found remote symptomatic etiology secondary to gliosis being the most common. ${ }^{14}$

Younger age along with central nervous system infection was an important factor for refractory status epilepticus which became malignant status epilepticus as reported by a study. These children had a longer duration of status epilepticus and thus a prolonged hospital stay and neurological disability. ${ }^{20}$ It was described in another study that likewise etiology, age is also a significant predictive factor for convulsive status epilepticus with remarkable difference across various age groups, being more common in extremes of age. ${ }^{17}$ 


\section{Refractory Status Epilepticus}

Contrary to this study, another study concluded that there was no significant relationship observed between RSE and the patients' age, gender and type of seizure. ${ }^{10}$ Though our study also concluded that there was a significant association between younger age, etiology and seizure type. The proportion of generalized seizures was $73.6 \%$ in a retrospective study on 189 children with status epilepticus and concluded that neurologic outcomes and recurrence of SE were found to be strongly associated with etiology and seizure type but age and seizure duration had no effect on outcome. ${ }^{21,22}$ In our study, generalized seizure type was also the most common seizure type $(53.3 \%)$. It was stated in a study that prolonged duration of status epilepticus before recovery had a significant impact and was associated with worse outcome. Quoted in another study, the longer duration of seizure activity, the greater the risk of morbidity and mortality and the same was reported in our study as well. ${ }^{23}$

\section{LIMITATION OF STUDY}

We did not identify the long-term consequences that a single episode of refractory seizures could cause in terms of cognitive, behavioural and sensory impairments.

\section{CONCLUSION}

Acute etiology and longer duration of refractory status epilepticus were associated with higher morbidity and mortality; however, return to baseline was also fair in the survivors. This poses implications for emergency management to focus on reducing the duration of status epilepticus for better outcomes.

\section{Conflict of Interest: None.}

\section{Authors' Contribution}

JRA: Concept, design, data collection, data analysis, manuscript writing, AW: Data collection, MA: Data collection, MAK: Data collection, ZUR: Manuscript review and editing, TS: Manuscript review, editing and final approval.

\section{REFERENCES}

1. Pujar S, Martinos MM, Borja CM, Chong KW, Haan DM, Gillberg C. Long-term prognosis after childhood convulsive status epilepticus: a prospective cohort study. Lancet 2018; 2(2): 103-111.

2. Tiamkao S, Pranbul S, Sawanyawisuth K, Thepsuthammarat K. Integrated epilepsy research group. a national database of incidence and treatment outcomes of status epilepticus in Thailand. Int J Neurosci 2014; 124(6): 416-420.

3. Dubey D, Kalita J, Misra UK. Status epilepticus: Refractory and super-refractory. Neurol Ind 2017; 65(7): 12-17.

4. Gurcharran K. The burden of pediatric status epilepticus: Epidemiology, morbidity, mortality and costs. Seiz 2019; 68(1): 3-8.
5. Walker MC. Pathophysiology of Status Epilepticus. Neurosci Lett 2018; 667(1); 84-91.

6. Trinka E, Cock H, Hesdorffer D, Rossetti OA, Scheffer EI, Shinnar S, et al. A Definition and classification of status epilepticus-report of the ILAE task force on classification of status Epilepticus. Epilepsia 2015; 56(10): 1515-1523.

7. Mitchell WG. Status epilepticus and acute repetitive seizures in children, adolescents, and young adults: etiology, outcome, and treatment. Epilepsia 1996; 37(1): S74-S80.

8. Vasquez A, Moeller RF, Tatum W. Pediatric refractory and super-refractory status epilepticus. Seiz 2019; 68(1): 62-71.

9. Jafarpour S, Hodgeman RM, Capeletto CDM, Kapur K, Tasker Rc, Loddenkemper T. New-Onset Status Epilepticus in Pediatric Patients: Causes, Characteristics, and Outcomes. Pediatr Neurol 2018; 80(1): 61-69.

10. Barzegar M, Mahdavi M, Behbehani AA, Tabrizi A. Refractory convulsive status epilepticus in children: etiology, associated risk factors and outcome. Iran J Child Neurol 2015; 9(4): 24-31.

11. Wheelar DS, Wong HR, Shanlet TP. The Central Nervous System and Pediatric critical illness and injury. [Internet] Available at: https://dl.uswr.ac.ir/bitstream/Hannan/139454/1/9781848009 929.pdf [Accessed on July 23, 2020].

12. Hocker S, Wijdicks EF, Rabinstein AA. Refractory status epilepticus: new insights in presentation, treatment, and outcome. Neurol Res 2013; 35(2): 163-168.

13. Hassan H, Rajiv KR, Menon R, Menon D, Nair M, Radhakrishnan A. An audit of the predictors of outcome in status epilepticus from a resource-poor country: a comparison with developed countries. Epileptic Disodr 2016; 18(2): 163-172.

14. Raspall-Chaure M, Chin RF, Neville BG, Scott RC. Outcome of pediatric convulsive status epilepticus: a systematic review. Lancet Neurol 2006; 5(9): 769-779.

15. Uzair M, Ibrahim A, Zafar F, Sultan T. Etiology and outcome of convulsive status epilepticus in children. Pak J Med Sci 2019; 35(3): 620-623.

16. Rossetti AO, Hurwitz S, Logroscino G, Bromfield EB. Prognosis of status epilepticus:role of aetiology, age, and consciousness impairment at presentation. J Neurol Neur 2006; 77(5): 611-615.

17. Sadik KC, Mishra D, Jhamb U. Clinico-etiological profile of pediatric refractory status epilepticus at a public hospital in India. J Epilepsy Res 2019; 9(1): 36-41.

18. Chin RFM. The outcomes of childhood co nvulsive status epilepticus. Epilepsy Behav 2019; 101(Pt-B): 106286.

19. Raspall-Chaure M, Chin RF, Neville BG, Bedford H, Scott RC. The epidemiology of convulsive status epilepticus in children:a critical review. Epilepsia 2007; 48(9): 1652-1663.

20. Holtkamp M, Othman J, Buchheim K, Masuhr F, Schielke E, Meierkord H. A "malignant" variant of status epilepticus. Arch. Neurol 2005; 62(9): 1428-1431.

21. Kang DC, Lee YM, Lee J, Kim HD, Coe C. Prognostic factors of status epilepticus in children. Yonsei Med J 2005; 46(1): 27-33.

22. Kafle DR, Avinash AJ, Shrestha A. Predictors of outcome in refractory generalized convulsive status epilepticus. Epilepsia Open 2020; 5(2): 248-254.

23. Gulati S, Kalra V, Sridhar MR. Status epilepticus in Indian children in a tertiary care center. Ind J Pediatr 2005; 72(2): 105108. 